\section{RSP}

http://www.rsp.fsp.usp.br/
Revista de Saúde Pública

\title{
A violência urbana é a maior causa de acidente de trabalho fatal no Brasil
}

Ricardo Cordeiro', Verônica Gronau Luz", Élida Azevedo Hennington"', Ana Cláudia Alves Martins ${ }^{\mathrm{IV}}$, Luís Fernando Tófoliv

' Universidade Estadual de Campinas. Faculdade de Ciências Médicas. Departamento de Saúde Coletiva. Campinas, SP, Brasil

" Universidade Federal da Grande Dourados. Faculdade de Ciências da Saúde. Curso de Nutrição. Dourados, MS, Brasil

III Fundação Oswaldo Cruz. Escola Nacional de Saúde Pública. Centro de Estudos da Saúde do Trabalhador e Ecologia Humana. Rio de Janeiro, RJ, Brasil

iv Universidade Estadual de Campinas. Faculdade de Ciências Médicas. Programa de Pós-Graduação em Saúde Coletiva. Campinas, SP, Brasil

$\checkmark$ Universidade Estadual de Campinas. Faculdade de Ciências Médicas. Departamento de Psicologia Médica e Psiquiatria. Campinas, SP, Brasil
Correspondência:

Ana Cláudia Alves Martins Departamento de Saúde Coletiva - Unicamp

Rua Tessália Vieira de Camargo, 126 13083-887 Campinas, SP, Brasil

E-mail: claudiarede@gmail.com

Recebido: 30 set 2016

Aprovado: 23 jan 2017

Como citar: Cordeiro R, Luz VG Hennington ÉA, Martins ACA, Tófoli LF. A violência urbana é a maior causa de acidente de trabalho fatal no Brasil. Rev Saude Publica. 2017;51:123.

Copyright: Este é um artigo de acesso aberto distribuído sob os termos da Licença de Atribuição Creative Commons, que permite uso irrestrito, distribuição e reprodução em qualquer meio, desde que o autor e a fonte originais sejam creditados.

\section{RESUMO}

OBJETIVO: Este estudo visou quantificar a ocorrência de mortes diretamente associadas à violência urbana dentre os acidentes de trabalho fatais.

MÉTODOS: Foram realizadas autópsias verbais com familiares e colegas de trabalho de moradores de Campinas, SP, falecidos por causas externas no ano 2015. Também foram analisados boletins de ocorrência e laudos do Instituto Médio Legal relativos a essas mortes.

RESULTADOS: Foram identificados 82 acidentes de trabalho fatais em Campinas em 2015, dos quais 25 foram assassinatos, 35 foram acidentes de trânsito não diretamente decorrentes de atividades laborais e três foram suicídios no trabalho. A mortalidade proporcional por homicídios, acidentes de trânsito e suicídios entre os acidentes de trabalho fatais foi estimada em 30,5\%, $42,7 \%$ e $3,7 \%$, respectivamente.

CONCLUSÕES: A violência urbana foi responsável por 3/4 dos acidentes de trabalho fatais contabilizados no período estudado.

DESCRITORES: Acidentes de Trabalho, Mortalidade. Causas Externas. Violência. Saúde do Trabalhador. 


\section{INTRODUÇÃO}

O acidente de trabalho é o maior agravo à saúde dos trabalhadores brasileiros. Somente no ano de 2013, em sua consolidação mais atual, o Ministério da Previdência Social do Brasil registrou a ocorrência de 702.685 acidentes de trabalho típicos e de trajeto em todo o território nacional ${ }^{12}$. Dentre os atingidos, 2.797 faleceram em consequência do acidente ${ }^{12}$, e a maior parte deles era constituída por trabalhadores jovens e produtivos. Destaque-se que esses dados são notoriamente sub-registrados no Brasil, conforme pesquisadores mostram ao longo das últimas décadas ${ }^{9,17,18}$.

Tradicionalmente, têm sido apontadas duas causas importantes para essa subnotificação. Por um lado, não existe um sistema único e eficiente que centralize as informações sobre AT no país. Os diferentes sistemas existentes têm efetividade limitada e pouco trocam informações entre si. Por outro lado, o banco de dados mais específico existente, do Ministério da Previdência Social, ignora os acidentes de trabalho ocorridos não apenas entre autônomos, funcionários públicos e proprietários, mas também aqueles que ocorrem no mercado informal da economia brasileira, que em 2012 abrangia 44,2 milhões de trabalhadores informais, equivalente a $56 \%$ da força de trabalho do país na ocasião ${ }^{21}$, e esse número segue proporcionalmente crescendo.

Entretanto, já há duas décadas, o crescimento da violência no Brasil e a dificuldade em identificar seus reflexos sobre a população trabalhadora têm sido sugeridos como fatores relevantes tanto para a ocorrência de acidente de trabalho, como para seu sub-registro no país. Muitos acidentes de trabalho fatais não são reconhecidos como relacionados ao trabalho, aparecendo nas estatísticas oficiais como homicídios comuns e acidentes em geral.

No Brasil, as mortes decorrentes de causas externas atingiram dois milhões de pessoas entre 1980 e 2000, período em que a mortalidade por homicídios aumentou $130 \%^{25}$. No início dos anos 2000, a mortalidade por causas externas diminuiu, passando a aumentar novamente a partir de 2008. Como não poderia deixar de ser, o aumento da violência tem seu impacto no mundo do trabalho, contribuindo de maneira importante para a conformação do perfil de mortalidade dos trabalhadores brasileiros nas últimas décadas. Diversos estudos realizados nesse período mostraram crescente participação de homicídios, latrocínios, suicídios, impacto de balas perdidas, acidentes de trânsito, sequestros e conflitos com criminosos, com colegas de trabalhos e com clientes e usuários como desencadeadores de acidentes de trabalho fatais ${ }^{3,10,20}$. Parte desses agravos é facilmente caracterizada como diretamente relacionada ao trabalho, como um vigia que morre baleado protegendo o patrimônio da empresa durante um assalto. Em outras ocasiões, a relação é menos direta, como no caso do trabalhador vítima de sequestro e assassinato quando volta do trabalho para casa.

Nos dias atuais, permanece relevante a investigação da mortalidade ocupacional em nosso meio, cuja gravidade é apenas tangenciada pelas estatísticas oficiais disponíveis. Para tanto, é necessário também entender e dimensionar a sua relação com a violência associada à criminalidade.

Frente à crescente violência vivenciada nos grandes centros urbanos, à magnitude da ocorrência de acidentes de trabalho no país e à relação entre esses dois agravos, este estudo visou quantificar, dentre os acidentes de trabalho, a ocorrência de mortes diretamente associadas à violência urbana, contribuindo para um melhor entendimento do quadro geral brasileiro.

\section{MÉTODOS}

O estudo foi realizado em Campinas, SP, município localizado 96 quilômetros a noroeste da cidade de São Paulo. Sua população em 2015 foi estimada em 1.164.098 habitantes ${ }^{4}$, sendo a terceira cidade mais populosa do estado de São Paulo e a décima quarta do país. 
Seu Índice de Desenvolvimento Humano era 0,805 em 2010, elevado no contexto brasileiro e um dos maiores do estado. A cidade é um polo industrial e tecnológico relativamente desenvolvido, que reflete bem a coexistência nada pacífica entre a riqueza e a pobreza nas grandes cidades brasileiras.

A Secretaria Municipal de Saúde de Campinas (SMS) recebe rotineiramente, de múltiplas fontes, a totalidade das declarações de óbitos dos falecidos moradores do município. Essas declarações são revisadas, complementadas e corrigidas quando necessário à luz de informações obtidas em hospitais, no Serviço de Verificação de Óbitos e no Instituto Médico Legal (IML) da cidade, reclassificando-se as causas básicas de óbito de acordo com as regras da $10^{a}$ Revisão da Classificação Internacional de Doenças (CID-10) ${ }^{16}$.

Foi enviado para a coordenação deste estudo, mediante parceria com a SMS, o conteúdo de todas as declarações de óbitos de moradores entre 15 e 65 anos do município de Campinas que faleceram em qualquer parte do território nacional entre 1/1/2015 e 31/12/2015 e cuja causa básica do óbito foi classificada, após revisão, como causa externa (isto é, dentro do capítulo XX da CID-10). A partir da informação sobre o local de residência, na parte III da declaração de óbito, a família do morador falecido foi localizada.

As informações para este trabalho foram coletadas principalmente por meio de entrevistas semiestruturadas realizadas por entrevistadores treinados em autópsia verbal ${ }^{1}$. Predominantemente, foram entrevistados familiares próximos do morador falecido (pais, cônjuges, irmãos, filhos), anotando-se as informações obtidas. Além de campos abertos para a livre narrativa dos entrevistados a respeito das circunstâncias que levaram seus familiares ao óbito, o questionário utilizado incluía dados sobre cor, religião, escolaridade, ocupação, situação de trabalho, uso de álcool, tabaco e drogas ilícitas. Sempre que necessário e possível, de modo análogo, foram também entrevistados vizinhos, amigos e colegas de trabalho do falecido. O número de entrevistas feitas para cada óbito identificado variou de acordo com a necessidade de complementação dos dados e a disponibilidade de informantes. Aos dados obtidos nas entrevistas, foram acrescentadas informações provenientes das análises dos laudos de necropsia realizados pelo IML de Campinas e de outras regiões e cópias dos boletins de ocorrências anexadas a esses laudos, bem como informações veiculadas na imprensa escrita e falada de Campinas a respeito dos óbitos investigados. Reuniões com toda a equipe da pesquisa, incluindo os pesquisadores de campo, foram realizadas semanalmente a fim de descrever e discutir os óbitos analisados e auxiliar na classificação final dos casos encontrados.

O trabalhador formal foi definido como aquele que, no momento do óbito, possuía contrato de trabalho regulamentar registrado (e.g., assalariados celetistas com carteira de trabalho assinada; funcionários públicos municipais, estaduais e federais regulamentados e com regime próprio de previdência; médicos residentes; trabalhadores autônomos regulamentados, como profissionais liberais, trabalhadores por conta própria, empresários e sócios-diretores de empresa, formalmente registrados e contribuintes da Previdência Social). Definiu-se o trabalhador informal como aquele que trabalhou sem contrato formal de trabalho nos trinta dias que precederam sua morte.

Os acidentes de trabalho foram definidos, conforme a Secretaria de Vigilância em Saúde do Ministério da Saúde (2014), como "aqueles que ocorrem no exercício da atividade laboral, ou no percurso de casa para o trabalho"13 (p. 752). O acidente de trabalho fatal foi definido como "aquele que leva a óbito imediatamente após sua ocorrência ou que venha a ocorrer posteriormente, a qualquer momento, em ambiente hospitalar ou não, desde que a causa básica, intermediária ou imediata da morte seja decorrente do acidente"13 (Ministério da Saúde, 2014, p.752).

A partir de todas as informações coletadas, os óbitos foram classificados ou como "acidentes do trabalho fatais" ou como "demais óbitos". Para os primeiros, ainda foi realizada uma re-entrevista com familiares e colegas de trabalho da vítima, para obtenção pormenorizada 
da história ocupacional do trabalhador falecido e controle de qualidade de campo. Para os propósitos desta análise, os acidentes de trabalho fatais encontrados foram classificados como:

- Acidentes de trabalho por crime (AT/cr): decorrentes primariamente de ato criminoso, intencional ou não, contra o trabalhador;

- Acidentes de trabalho estritos (AT/es): excluída a classe anterior, são aqueles originados primariamente na execução de atividades laborais;

- Acidentes de trabalho no trânsito (AT/tr): excluídas as classes anteriores, são aqueles decorrentes primariamente de colisões, atropelamentos ou quedas de veículos motorizados ou não no trânsito, bem como desequilíbrios ou quedas do trabalhador durante locomoção a pé;

- Outros acidentes de trabalho(AT/ou): acidentes não enquadrados em nenhuma classe anterior.

As atividades de campo foram iniciadas após o estudo receber parecer favorável do Comitê de Ética em Pesquisa da Faculdade de Ciências Médicas da Universidade Estadual de Campinas (Parecer 918.561).

\section{RESULTADOS}

Foram encontrados 415 óbitos de moradores de Campinas com idade entre 15 e 65 anos cujas causas básicas eram externas.

Ao analisar-se os laudos de necropsia elaborados pelo IML para esses óbitos, constatou-se que 32 deles, de fato, não foram decorrentes de causas externas, mas sim mortes naturais. Essas foram excluídas do universo estudado, restando 383 mortes violentas a serem analisadas. Dessas, cinco (1,3\%) não foram investigadas porque não se conseguiu identificar nenhum parente, amigo ou colega de trabalho do falecido, sendo consideradas perdas. Desse modo, os resultados aqui apresentados referem-se a 378 mortes violentas de moradores de Campinas com idade entre 15 e 65 anos ocorridas em 2015 na cidade ou fora dela.

A Tabela 1 mostra a classificação desses óbitos segundo causa imediata.

Dentre as 378 mortes violentas encontradas, 82 foram classificadas como acidente de trabalho, o que correspondeu a uma mortalidade proporcional de $21,7 \%$. Isto é, em cada cinco mortes violentas acontecendo nessa faixa etária entre moradores de Campinas, uma foi causada por acidente de trabalho.

Chama atenção a magnitude da incidência de acidente de trabalho fatal em Campinas. Levando-se em consideração o tamanho da população sob risco de sofrer acidente de trabalho na cidade 4 , em 2015 foram identificados 10 acidentes de trabalho fatais para cada 100 mil moradores em idade economicamente ativa. Para o sexo masculino, esse coeficiente foi de 17,9 óbitos por 100 mil habitantes nessa faixa etária.

Tabela 1. Distribuição das mortes violentas dos residentes em Campinas, SP, com idade entre 15 e 65 anos, segundo causa imediata, no ano de 2015.

\begin{tabular}{lccc}
\hline Causa imediata & Frequência absoluta (n) & Frequência relativa (\%) & $\begin{array}{c}\text { Acidente de trabalho } \\
\text { (absoluto e relativo) }\end{array}$ \\
\hline Homicídio & 160 & 42,3 & $25(15,6)$ \\
Acidente de trânsito & 117 & 30,9 & $42(35,9)$ \\
Suicídio & 48 & 12,7 & $3(6,3)$ \\
Queda & 37 & 9,8 & $3(8,1)$ \\
Afogamento & 6 & 1,6 & $0(0)$ \\
Outros & 10 & 2,6 & $9(90,0)$ \\
\hline Total & 378 & 100 & $82(21,7)$ \\
\hline
\end{tabular}

Na coluna 'Acidente de trabalho (absoluto e relativo)' são apresentados o número absoluto de acidentes do trabalho segundo a causa imediata correspondente e sua proporção nessa categoria, em procentagem. 
Os dados apresentados a seguir referem-se aos 82 trabalhadores vítimas de acidentes de trabalho identificados. Dentre as declarações de óbito analisadas, 27 (32,9\%) traziam o campo "Acidente do Trabalho" marcado como "não", 50 (61,0\%) marcados como "ignorado" e apenas cinco $(6,1 \%)$ marcados como "sim". Uma vez que essa é a fonte de dados que alimenta o Sistema de Informação de Mortalidade ${ }^{14}$ (SIM), do Ministério da Saúde, conclui-se que o sub-registro de acidente de trabalho fatal nos dados do SIM para Campinas nesse período seria de 93,9\%, se essa informação não fosse corrigida a partir dos dados desta pesquisa.

Quanto ao sexo, 74 (90,2\%) trabalhadores eram homens e oito (9,8\%) eram mulheres. A média e a mediana de idade ao morrer foram 42 e 43 anos, respectivamente. $\mathrm{O}$ trabalhador mais jovem tinha 18 anos e o mais velho 63 anos. A escolaridade média e mediana do grupo, medida em anos completos, foi de sete e oito anos, respectivamente, variando entre zero e 16 anos.

A Tabela 2 apresenta a distribuição das ocupações dos 82 trabalhadores falecidos, segundo Grandes Grupos da Classificação Brasileira de Ocupações ${ }^{15}$.

Com relação à regulamentação do trabalho no momento do óbito, encontrou-se $62(75,6 \%)$ trabalhadores formais (dos quais 15 eram autônomos regulamentados), 12 (14,6\%) informais e oito $(9,8 \%)$ trabalhadores com vínculo empregatício desconhecido.

Quanto à cor, $42(51,2 \%)$ eram brancos, $31(37,8 \%)$ pardos e nove $(11,0 \%)$ eram pretos. Quanto à religião, $41(50,0 \%)$ eram católicos, $27(32,9 \%)$ eram evangélicos, quatro $(4,9 \%)$ eram espíritas, um (1,2\%) era umbandista, cinco $(6,1 \%)$ não tinham religião e quatro $(4,9 \%)$ tinham religião desconhecida.

$\mathrm{Na}$ avaliação do uso de drogas lícitas e ilícitas dentre os trabalhadores que vieram a óbito, $50(61,0 \%)$ usavam álcool no mês do óbito, 28 (34,1\%) fumavam, 13 (15,9\%) faziam uso de drogas ilícitas e $14(17,1 \%)$ apresentavam uso problemático de álcool ou drogas ilícitas.

Dentre os 82 acidentes de trabalho fatais identificados, 64 (78,4\%) aconteceram em ruas, praças ou rodovias. Cinquenta $(61,0 \%)$ deles ocorreram fora dos ambientes de trabalho dos trabalhadores envolvidos.

A Tabela 3 apresenta a classificação dos acidentes de trabalho fatais analisados.

É surpreendente a quantidade encontrada de ações criminosas contra o trabalhador. Cerca de 1/3 dos acidentes de trabalho fatais ocorridos em Campinas foram resultantes de homicídios.

No Quadro 1 é apresentada uma descrição resumida dos 25 acidentes de trabalho classificados como decorrentes de atos criminosos (AT/cr).

Tabela 2. Classificação das ocupações dos trabalhadores mortos em 2015, residentes em Campinas, SP, segundo Grandes Grupos da Classificação Brasileira de Ocupações.

\begin{tabular}{lcc}
\hline Grandes grupos & Frequência absoluta (n) & Frequência relativa (\%) \\
\hline 7: Trabalhadores da produção de bens e serviços industriais, exceto operadores de máquinas & 28 & 34,1 \\
5: Trabalhadores dos serviços, vendedores do comércio em lojas e mercados & 28 & 7 \\
4: Trabalhadores de serviços administrativos & 5 & 34,1 \\
1: Membros superiores do poder público, dirigentes de organizações de interesse público e de & 4,5 \\
empresas e gerentes & 3 & 4,1 \\
2: Profissionais das ciências e das artes & 3 & 3,9 \\
6: Trabalhadores agropecuários, florestais, da caça e pesca & 1 & 3,7 \\
9: Trabalhadores de manutenção e reparação & 1 & 1,2 \\
0: Forças armadas, policiais e bombeiros militares & 1 & 1,2 \\
3: Técnico de nível médio & 1 & 1,2 \\
8: Trabalhadores da produção de bens e serviços industriais, apenas operadores de máquinas & 82 \\
Sem informação & 1,2 \\
\hline Total & 100 \\
\hline
\end{tabular}


Tabela 3. Distribuição dos acidentes de trabalho fatais em 2015, dos residentes em Campinas, SP, segundo tipo.

\begin{tabular}{lcc}
\hline Tipo de acidente de trabalho & Frequência absoluta $(\mathbf{n})$ & Frequência relativa (\%) \\
\hline Acidentes de trabalho por crime & 25 & 30,5 \\
Acidentes de trabalho estritos & 19 & 23,2 \\
Acidentes de trabalho no trânsito & 35 & 42,7 \\
Outros acidentes de trabalho & 3 & 3,7 \\
\hline Total & 82 & 100 \\
\hline
\end{tabular}

Quadro 1. Descrição resumida dos 25 acidentes de trabalho diretamente decorrentes de atos criminosos ocorridos entre trabalhadores moradores de Campinas, SP, em 2015.

\begin{tabular}{|c|c|}
\hline Caso & Descrição \\
\hline 16 & $\begin{array}{l}\text { Motorista de ônibus, quando voltava a pé do terminal de ônibus para casa foi espancado e asfixiado por } \\
\text { dois desconhecidos. Motivação: possível desentendimento com traficantes. }\end{array}$ \\
\hline 24 & $\begin{array}{l}\text { Cozinheira, foi retirada do trabalho a força por dois desconhecidos, que jogaram um galão de gasolina } \\
\text { sobre seu corpo e colocaram fogo. Motivação: possível crime passional }\end{array}$ \\
\hline 41 & $\begin{array}{l}\text { Montador de esquadrias metálicas, transportava material para uma obra em carro da empresa. Parado em } \\
\text { um engarrafamento, foi abordado por três desconhecidos. Um deles disparou dois tiros no trabalhador. } \\
\text { Motivação: possivelmente confundido com pessoa jurada de morte. }\end{array}$ \\
\hline 42 & $\begin{array}{l}\text { Trabalhador rural, enquanto podava goiabeiras em um pomar foi abordado por um desconhecido que } \\
\text { chegou em uma motocicleta e atirou três vezes contra o trabalhador. Motivação: possível crime passional. }\end{array}$ \\
\hline 64 & $\begin{array}{l}\text { Chefe de manutenção em um grande hotel, na saída do trabalho foi atac } \\
\text { espancaram até a morte. Motivação: possivelmente confundido c }\end{array}$ \\
\hline 76 & $\begin{array}{l}\text { Trabalhadora do sexo (CBO 5198-05), foi esfaqueada por um cliente durante relacionamento sexual. } \\
\text { Motivação: desentendimento com cliente relativo ao preço do programa. }\end{array}$ \\
\hline 78 & $\begin{array}{l}\text { Mecânico, foi socorrer carro quebrado em uma rua. Enqı } \\
\text { desconhecidos que dispararam dois tiros contra }\end{array}$ \\
\hline 110 & $\begin{array}{l}\text { Vigia de condomínio, trabalhava dentro de uma guarita e recebeu três tiros pelas costas, d } \\
\text { por um desconhecido encapuçado. Motivação: possível crime passional. }\end{array}$ \\
\hline 121 & $\begin{array}{l}\text { Chapeiro de uma lanchonete, recebeu vários tiros disparados por desconhecidos quando voltava para } \\
\text { casa, vindo do trabalho. Motivação: possível desentendimento com traficantes. }\end{array}$ \\
\hline 123 & $\begin{array}{c}\text { Catadora de material reciclável, foi atropelada por um ônibus, manobrando para entrar em uma } \\
\text { garagem, enquanto recolhia papelão na rua. Motivação: atropelamento acidental enquanto } \\
\text { desempenhava atividade de trabalho. }\end{array}$ \\
\hline 149 & Vendedor de cachorro quente, baleado por desconhecido ao reagir a um assalto. Motivação: latrocínio. \\
\hline 155 & $\begin{array}{r}\text { Faxineiro de um clube esportivo, foi esfaqueado durante o expediente por c } \\
\text { desentendimento com colega de trabalho. }\end{array}$ \\
\hline 159 & Marceneiro, recebeu vários tiros ao reagir a assalto a caminho do trabalho. Motivação: latrocínio. \\
\hline 174 & $\begin{array}{l}\text { Pizzaiolo, proprietário de uma pequena pizzaria, saiu do trabalho e foi até su } \\
\text { pegar insumos. Ao descer do carro recebeu cinco tiros. Motivaçãe }\end{array}$ \\
\hline 187 & $\begin{array}{l}\text { Porteiro de prédio, foi roubado, espancado e morto por três adolescentes desconhecidos saindo do prédio } \\
\text { ao final do expediente e dirigindo-se para casa. Motivação: latrocínio. }\end{array}$ \\
\hline 211 & $\begin{array}{l}\text { Operador de fotocopiadora, foi sequestrado ao sair do trabalho p } \\
\text { abandonado no acostamento de uma rodovia. Motivação: }\end{array}$ \\
\hline 218 & $\begin{array}{l}\text { Proprietário de uma papelaria, foi sequestrado na porta do trabalho por dois desconhecidos } \\
\text { armados. Seu corpo foi encontrado em um matagal dias depois com marcas de espancamento. } \\
\text { Motivação: desconhecida. }\end{array}$ \\
\hline 219 & $\begin{array}{l}\text { Dono de bar na periferia, enquanto trabalhava foi atingido por vários tiros disparados por um cliente. } \\
\text { Motivação: desentendimento com cliente relativo a preço de bebida. }\end{array}$ \\
\hline 220 & $\begin{array}{l}\text { Agente penitenciário, após sair do trabalho dirigia seu automóvel para casa quando foi abordado } \\
\text { por dois ocupantes de uma moto. O carona disparou dez tiros contra o agente. Motivação: possível } \\
\text { desentendimento com traficantes. }\end{array}$ \\
\hline 247 & $\begin{array}{c}\text { Pedreiro, a caminho de casa saindo do trabalho, foi espancado e morto pelo filho do patrão. Motivação: } \\
\text { desentendimento com terceiro. }\end{array}$ \\
\hline 280 & $\begin{array}{c}\text { Auxiliar de supermercado, foi atropelado na porta do trabalho, enquanto descarregava mercadorias, } \\
\text { por um automóvel que invadiu a calçada. O automóvel acabara de ser roubado e o motorista estava } \\
\text { sendo perseguido pela polícia no momento do acidente. Motivação: atropelamento acidental enquanto } \\
\text { desempenhava atividade de trabalho. }\end{array}$ \\
\hline 321 & $\begin{array}{l}\text { Vigia de uma empresa de transportes, durante ronda recebeu dois disparos de fuzil feitos por um } \\
\text { desconhecido. Motivação: possivelmente confundido com pessoa jurada de morte. }\end{array}$ \\
\hline 324 & Vigia de lanchonete, entrou em confronto com dois assaltantes no local do trabalho e foi baleado. \\
\hline 359 & Dona de um bar, foi baleada por um cliente. Motivação: desentendimento quanto ao troco de bebida. \\
\hline 383 & $\begin{array}{l}\text { Motorista de um micro-ônibus, morreu executado a tiros por um passageiro enquanto dirigia. Motivação: } \\
\text { possível desentendimento com criminosos. }\end{array}$ \\
\hline
\end{tabular}


Dentre os 25 trabalhadores vítimas de AT/cr, 19 (76,0\%) trabalhavam ou faziam seus percursos entre casa e trabalho sós, isto é, sem a companhia de outros colegas de trabalho. Também dentre esses, 11 (44,0\%) foram vítimas das ações criminosas que os levaram a óbito tarde da noite ou de madrugada, e 10 (40,0\%) morreram em áreas urbanas consideradas de alta criminalidade.

O Quadro 2 descreve resumidamente os 19 acidentes de trabalho classificados como estritamente relacionados a atividades laborais (AT/es).

Os $35(42,7 \%)$ acidentes de trabalho classificados como AT/tr foram decorrentes de colisões e atropelamentos em vias urbanas e rodovias. Os três $(3,7 \%)$ acidentes classificados como AT/ou foram decorrentes de suicídio, todos cometidos no ambiente de trabalho durante o expediente. Em um deles, um trabalhador braçal, exposto cronicamente a organofosforados, enforcou-se enquanto aparava grama em um jardim público. Em outro, um pintor industrial, exposto cronicamente a solventes orgânicos, atirou-se deliberadamente contra um ônibus que passava em frente ao portão da indústria na saída do trabalho. O terceiro trabalhador era o proprietário de uma pequena marcenaria que se enforcou em seu escritório durante o expediente, deixando uma carta onde dizia que não suportava mais a pressão de credores à porta de seu estabelecimento exigindo pagamentos em atraso.

Quadro 2. Descrição resumida dos 19 acidentes de trabalho estritamente relacionados a atividades laborais ocorridos entre trabalhadores moradores de Campinas, SP, em 2015.

\begin{tabular}{|c|c|}
\hline Caso & Descrição \\
\hline 25 & Pedreiro, assentava telhas em um telhado, desequilibrou-se e caiu ao solo. \\
\hline 95 & $\begin{array}{l}\text { Trabalhador de empresa concessionária de rodovias, foi atropelado no acostamento enquanto } \\
\text { pintava faixa de segurança em uma rodovia. }\end{array}$ \\
\hline 100 & $\begin{array}{l}\text { Instalador de painéis, foi vítima de queda de um "outdoor" sobre seu corpo enquanto trabalhava } \\
\text { em sua fixação. }\end{array}$ \\
\hline 119 & Tratador de cavalos, sofreu trauma no tórax decorrente de coice de cavalo que tratava. \\
\hline 126 & Caminhoneiro, caiu da carroceria do caminhão enquanto descarregava telhas. \\
\hline 131 & Vigilante, sofreu acidente automobilístico em rodovia enquanto escoltava caminhão. \\
\hline 137 & Caminhoneiro, sofreu acidente automobilístico em rodovia enquanto transportava carga. \\
\hline 138 & Vendedor ambulante, foi atropelado no acostamento de rodovia enquanto vendia frutas. \\
\hline 160 & $\begin{array}{l}\text { Trabalhador da construção civil, foi esmagado por blocos de mármore que caíram da carroceria } \\
\text { de um caminhão que descarregava. }\end{array}$ \\
\hline 215 & Pedreiro, assentava telhas em um telhado, desequilibrou-se e caiu ao solo. \\
\hline 221 & $\begin{array}{l}\text { Catador de recicláveis, enquanto recolhia material foi eletrocutado ao tentar afastar da calçada } \\
\text { um fio desencapado de alta tensão que havia caído de um poste. }\end{array}$ \\
\hline 222 & $\begin{array}{c}\text { Motorista de ônibus, auxiliava cadeirante entrar no veículo quando escorregou e caiu batendo a } \\
\text { cabeça na guia. }\end{array}$ \\
\hline 246 & $\begin{array}{l}\text { Motorista de caminhão, estacionou o veículo numa rampa, desceu e foi para trás do caminhão. } \\
\text { Nesse momento, o sistema de freio falhou, o caminhão desceu e prensou o motorista contra outro } \\
\text { caminhão estacionado. }\end{array}$ \\
\hline 295 & $\begin{array}{l}\text { Pedreiro, dirigia a trabalho um trator em uma estrada de terra em acentuado declive, perdeu o } \\
\text { controle do veículo e capotou. }\end{array}$ \\
\hline 303 & $\begin{array}{l}\text { Eletricista, foi eletrocutado e caiu do alto de um poste enquanto fazia uma ligação clandestina } \\
\text { ("gato"). }\end{array}$ \\
\hline 314 & $\begin{array}{c}\text { Entregador de encomendas, colidiu sua moto contra um automóvel enquanto trazia peças para um } \\
\text { estacionamento. }\end{array}$ \\
\hline 340 & $\begin{array}{l}\text { Pedreiro, enquanto trabalhava em um canteiro de obras foi soterrado por um muro alto que } \\
\text { desabou sobre ele. }\end{array}$ \\
\hline 403 & $\begin{array}{l}\text { Pedreiro, enquanto trabalhava num canteiro de obras foi atingido por um caibro que caiu do } \\
\text { oitavo andar de um prédio em construção. }\end{array}$ \\
\hline 411 & $\begin{array}{l}\text { Motorista de caminhão, transportava mercadorias, parou no acostamento para atender telefone, } \\
\text { desceu do caminhão e foi atropelado por automóvel. }\end{array}$ \\
\hline
\end{tabular}




\section{DISCUSSÃO}

A quantidade de acidentes de trabalho encontrada é, por si só, alarmante; principalmente, porque refere-se a eventos absolutamente evitáveis, que expressam negligência e injustiça social ${ }^{19}$.

Neste estudo, evitou-se utilizar a clássica categorização dos acidentes de trabalho como "típicos" e "de trajeto". Isso porque esses termos induzem, ao menos no senso comum, a uma concepção desatualizada, e mesmo equivocada. $\mathrm{O}$ acidente de trabalho não pode ser rotulado como típico. Típico é aquilo que normalmente acontece, que é característico, que serve de modelo. O Ministério da Previdência Social do Brasil chama de típico os acidentes "decorrentes da característica da atividade profissional desempenhada pelo acidentado"12, uma definição que naturaliza o acidente de trabalho, limita seu reconhecimento e o atribui a situações mais ou menos esperadas e restritas ao desempenho de atividades laborais. Também não se utilizou a categoria "de trajeto" porque esse termo não especifica o acidente. No trajeto, o trabalhador sofre não apenas acidentes circunscritos à sua locomoção, mas também acidentes estritamente decorrentes de sua atividade laboral, bem como ações intencionalmente criminosas. Além disso, a utilização da categoria "de trajeto" não raramente leva a intermináveis discussões de interesse estritamente pecuniário sobre natureza do trajeto, habitualidade do trajeto, alterações do trajeto, interrupções intencionais do trajeto, etc.

O estudo do trabalho e suas repercussões na vida do trabalhador deve implicar não apenas a análise de questões diretamente ligadas ao trabalho, mas também na sua articulação com toda a sociedade da qual é produto e com a qual interage ${ }^{11}$. A classificação de acidentes de trabalho aqui utilizada categorizou os acidentes fatais como AT/cr, AT/es, AT/tr e AT/ou com duas intenções. Por um lado, ressaltar que a organização do trabalho e os modos como o trabalhador desenvolve suas atividades laborais são apenas uma parte importante do problema. Por outro lado, dar maior visibilidade aos reflexos das mudanças no mercado de trabalho em décadas recentes (com a expansão do setor de serviços e a maior exposição do trabalhador ao ambiente da rua) no atual contexto da violência social brasileira, expresso pela criminalidade, pela agressividade do trânsito e pelo aumento da incidência do suicídio8.

Dentre todos os acidentes de trabalho fatais encontrados, $30,5 \%$ foram classificados como AT/cr. Os AT/cr resultam de ações criminosas praticadas, intencionalmente ou não, por colegas de trabalho, clientes, público em geral, criminosos, policiais etc. Não bastasse o enorme sub-registro de acidentes do trabalho fatais devido ao alijamento da grande maioria da população trabalhadora do sistema oficial de notificação de AT; não bastasse o sub-registro de acidentes de trabalho fatais, mesmo para a parcela de trabalhadores que oficialmente fazem jus a esse direito, devido a falhas de notificação do sistema; também os AT/cr geralmente não são reconhecidos como acidentes de trabalho, sendo classificados nas estatísticas oficiais como violência comum (termo que por si só denuncia a gravidade e a banalização da violência em nosso meio), contribuindo para a invisibilidade das situações adversas de trabalho responsáveis pela sua ocorrência?

Souza et al. (2006) referem que "homicídios relacionados ao trabalho estariam condicionados a fatores de risco próprios de algumas atividades: trabalho solitário ou em grupos reduzidos, intercâmbio de dinheiro com o público, trabalho realizado nas últimas horas da noite ou nas primeiras da manhã, trabalho em zonas de alta criminalidade, custódia de bens de valor e trabalho nas ruas"22 (p. 87). Essa impressão é compatível com os achados aqui apresentados. Conforme visto, dentre os $25 \mathrm{AT} / \mathrm{cr}$ identificados, 76,0\% ocorreram em situações onde o trabalhador estava só em seu posto de trabalho ou na rua, $44,0 \%$ ocorreram tarde da noite ou de madrugada e 40,0\% ocorreram em áreas urbanas de alta criminalidade. A violência social no Brasil é um fenômeno complexo, cujas raízes se aninham nas desigualdades sociais que o país criou ao longo de seu desenvolvimento. O controle da violência e de seus reflexos 
no mundo do trabalho é também uma questão complexa e macroestrutural. Sob um caráter emergencial e paliativo, pode-se identificar que as situações acima listadas são riscos que, quando possível, devem ser evitados visando à diminuição da ocorrência de AT/cr.

Com relação aos 19 AT/es identificados, mais da metade ocorreu em situações como quedas de altura, queda de objetos pesados sobre o corpo, eletrocussão e soterramento, ou seja, eventos para os quais a legislação vigente já prescreve a adoção de barreiras de prevenção, monitoramento e mitigação de efeitos. Cabe aos Centros de Referência em Saúde do Trabalhador (CEREST) e às representações dos trabalhadores atuar politicamente para que a lei seja cumprida.

Também dentre os acidentes de trabalho fatais analisados, $42,7 \%$ foram classificados como AT/tr.Já excluídos os AT/cr e os AT/es, esses 42,7\% referem-se apenas a acidentes de trânsito, correspondentes a atropelamentos, colisões entre carros ou motos e quedas de veículos em movimento. Além dos reflexos da saturação de automóveis nas grandes cidades e da política de transporte brasileira que privilegia o transporte individual em detrimento do coletivo, não se pode deixar de reconhecer que os AT/tr têm também como um dos componentes de sua gênese, sob um olhar epidemiológico, o estresse físico e mental a que os trabalhadores estão submetidos. Também esses acidentes, em sua maioria, não são reconhecidos nas estatísticas oficiais como acidentes de trabalho. Constatamos que a grande maioria das famílias das vítimas de AT/tr se preocupou com os trâmites necessários para obtenção do seguro DPVAT ${ }^{23}$, seguro esse amplamente divulgado nos meios de comunicação. Já o reconhecimento do AT/tr como relacionado ao trabalho e as iniciativas para obtenção da pensão por morte acidentária ${ }^{12}$ por parte dos familiares dos trabalhadores celetistas mortos foram minoritárias.

AT/cr, AT/tr e AT/ou foram responsáveis por três quartos dos acidentes de trabalho fatais aqui analisados. De fato, $78,4 \%$ dos acidentes de trabalho fatais identificados ocorreram em ruas, praças e rodovias. Também se observou que $61,0 \%$ dos acidentes de trabalho fatais ocorreram fora do ambiente de trabalho de suas vítimas. Isso reforça a necessidade de repensar as estratégias de prevenção dos acidentes de trabalho e de salvaguarda da saúde dos trabalhadores brasileiros. Ações preventivas na área da Saúde do Trabalhador precisam ultrapassar os limites do "espaço da fábrica" e agir sobre essa realidade.

É necessário repensar também o sistema de informação de modo a melhorar a identificação desse tipo de evento, contribuindo para a construção de intervenções efetivas para minorar os riscos e prevenir acidentes de trabalho absolutamente evitáveis. Para tanto, contribui compreender o acidente de trabalho como qualquer evento agudo, intencional ou fortuito, que provoque a morte do trabalhador ou que afete sua integridade física ou mental, ocorrido durante o exercício do trabalho ou em deslocamentos necessários para a sua realização. Essa concepção é diferente da oficial, preconizada pelo Ministério da Previdência Social (Lei 8213, 1991). Sob esse ponto de vista, a informação fundamental a ser obtida é: qual era a atividade do indivíduo no momento do acidente que o levou à morte? Essa concepção de acidente de trabalho e a preocupação em investigar essa pergunta geralmente não são contempladas pelas equipes que alimentam o SIM nos municípios. Contribuiria, na redução da invisibilidade dos acidentes de trabalho, discutir e atualizar o conceito de acidente de trabalho na sociedade como um todo e em particular entre os profissionais e estudantes da área da saúde. A relação entre a violência social e os acidentes de trabalho também precisa ser discutida. Adicionalmente, deve-se atualizar protocolos e treinar as equipes de coleta de dados o mais amplamente possível nos municípios brasileiros, sob esse entendimento. Esse último é um investimento custoso, difícil, em longo prazo, e que apenas trará resultados se for complementar ao anteriormente proposto.

É interessante observar que, neste estudo, dentre os falecidos, prevaleceram amplamente os trabalhadores formais $(75,6 \%)$ em relação aos informais. No estudo realizado por Hennington et al. ${ }^{3}$, com dados coletados há 15 anos com método semelhante também em Campinas, apenas $30 \%$ dos trabalhadores mortos eram formais. No estudo de Lacerda et al. ${ }^{6}$, cujos 
dados foram coletados há 11 anos em Salvador, também apenas 1/3 dos trabalhadores mortos foram classificados como formais. Talvez essa discrepância se deva, parcialmente, ao aumento da proporção de empregos formais ocorrida em Campinas na última década. De acordo com a Relação Anual de Informações Sociais (RAIS) de 2014, o nível de emprego formal cresceu 1,27\% em relação a 2013, com o incremento de 623.077 postos de trabalho, confirmando a trajetória de crescimento do emprego formal no país entre 2010 e 2015. Segundo a Fundação Seade 2 , a região administrativa de Campinas representa 15,9\% dos empregos formais do estado. Estima-se que, em julho de 2015, a proporção de trabalhadores formais na Região Metropolitana de São Paulo, a menos de 100 km de Campinas, era 57\% da população ocupada ${ }^{5}$, um dado que pode ser extrapolado para Campinas.

É notável que as perdas de informação deste estudo foram devidas à não identificação de informantes sobre apenas cinco (1,3\%) óbitos do total de 383 mortes violentas acontecidas em Campinas em 2015. Alguns fatores contribuíram para isso. As entrevistas, em sua grande maioria, foram realizadas cerca de uma a duas semanas após a ocorrência dos óbitos, exceção feita para aqueles que faleceram fora de Campinas. Isso minimizou a ocorrência de problemas decorrentes de mudanças de endereços de familiares após o óbito. E, quando havia mudança de endereço, era possível entrevistar vizinhos e colegas de trabalho. A utilização de informações sobre ocorrências de mortes violentas obtidas na imprensa escrita e falada também foi importante, não apenas para a identificação de informantes, mas principalmente para o enriquecimento das histórias. Em que pese a cautela com o comportamento sensacionalista de muitos veículos de divulgação desse tipo de notícia, - que frequentemente supervalorizam aspectos em investigação -, alguns autores têm indicado que jornais são uma importante fonte complementar de qualificação e complementação de informações sobre óbitos por causas externas ${ }^{24}$, inclusive especificamente no que se refere a acidentes de trabalho fatais ${ }^{22}$.

\section{CONSIDERAÇÕES FINAIS}

Em Campinas vivem mais de um milhão e cem mil pessoas. A cidade é sede de uma das Regiões Metropolitanas do Brasil. A situação aqui descrita não parece ser um caso particular. Ao contrário, esse parece ser o quadro encontrado, em maior ou menor gravidade, em todo o país. Ao lado de antigos problemas, a deterioração do cenário político, social, econômico e ambiental brasileiro acarreta grande transformação nas relações sociais e de trabalho. A crescente desregulamentação e precarização do trabalho, o aumento do desemprego e a presença de grupos organizados mediando conflitos à margem do Estado nas periferias dos grandes centros urbanos impuseram significativa alteração no perfil de mortalidade dos trabalhadores brasileiros. Hoje, qualquer ação preventiva na área da Saúde do Trabalhador deve contemplar essa realidade. Assim fazendo, poderemos sonhar com a implantação de medidas mais efetivas de prevenção e controle dos acidentes de trabalho, começando a resgatar uma dívida com milhões de trabalhadores brasileiros que lutam diariamente pela sobrevivência, que contribuem com seu trabalho para o desenvolvimento do Brasil, cujos acidentes nem ao menos são computados e cujas famílias tampouco podem desfrutar de amparo e solidariedade.

\section{REFERÊNCIAS}

1. AbouZahr C, Bahl R, Bartlett L, Rhutta Z, Bial S, Boerma T, et al . Verbal autopsy standards: ascertaining and attributing cause of death. Geneva; WHO Press; 2007 [citado 27 set 2016]. Disponível em: http://apps.who.int/iris/bitstream/10665/43764/1/9789241547215_eng.pdf

2. Fundação SEADE. Painel das Profissões: emprego formal RA de Campinas: $3^{\circ}$ trimestre de 2015. São Paulo; 2015 [citado 27 set 2016]. Disponível em http://www.seade.gov.br/profissoes/wpcontent/uploads/2016/01/painel_Profis_RACampinas_3trim2015.pdf 
3. Henington EA, Cordeiro R, Moreira Filho DC. Trabalho, violência e morte em Campinas, São Paulo, Brasil. Cad Saude Publica. 2004;20(2):610-7. https://doi.org/10.1590/S0102-311X2004000200031

4. Instituto Brasileiro de Geograria e Estatística. Cidades @: São Paulo: Campinas: estimativa da população 2016. Rio de Janeiro: IBGE; 2016 [citado 27 set 2016]. Disponível em http://www. cidades.ibge.gov.br/xtras/temas.php?lang=\&codmun=350950\&idtema=130\&search=saopaulocampinasestimativa-da-populacao-2015

5. Instituto Brasileiro de Geograria e Estatística. Pesquisa mensal de emprego. Rio de Janeiro: IBGE; 2016 [citado 27 set 2016]. Disponível em: www.ibge.gov.br/home/estatistica/indicadores/ trabalhoerendimento/pme_nova/defaulttab2.shtm

6. Lacerda KM, Fernandes RCP, Nobre LCC. Acidentes de trabalho fatais em Salvador, BA: descrevendo o evento subnotificado e sua relação com a violência urbana. Rev Bras Saude Ocup. 2014;39(129):63-74. https://doi.org/10.1590/0303-7657000064812

7. Lacerda KM, Fernandes RCP, Nobre LCC, Pena PGL. A (in)visibilidade do acidente de trabalho fatal entre as causas externas: estudo qualitativo. Rev Bras Saude Ocup. 2014;39(130):127-35. https://doi.org/10.1590/0303-7657000068112

8. Lovisi GM, Santos SA, Legay L, Abelha L, Valencia E. Análise epidemiológica do suicídio no Brasil entre 1980 e 2006. Rev Bras Psiquiatr. 2009;31 Supl 2:S86-94. https://doi.org/10.1590/S1516-44462009000600007

9. Lucca SR, Fávero M. Os acidentes do trabalho no Brasil: algumas implicações de ordem econômica, social e legal. Rev Bras Saude Ocup. 1994 [citado 27 set 2016];22(81):7-14. Disponível em: http://www.fundacentro.gov.br/arquivos/rbso/Artigos\%2081/V22\%20n81-02.pdf

10. Machado JMH, Gomez CM. Acidentes de trabalho: uma expressão da violência social. Cad Saude Publica. 1994;10 Supl1:S74-87. https://doi.org/10.1590/S0102-311X1994000500006

11. Mendes JMR. O verso e o anverso de uma história: o acidente e a morte no trabalho. Porto Alegre; EDIPUCRS; 2003.

12. Ministério da Previdência Social (BR). AEPS 2013 - Anuário Estatístico da Previdência Social 2013. Brasília (DF), Seção IV; 2016 [citado 27 set 2016]. Disponível em: http://www. previdencia.gov.br/dados-abertos/aeps-2013-anuario-estatistico-da-previdencia-social-2013/ aeps-2013-secao-iv-acidentes-do-trabalho/

13. Ministério da Saúde (BR), Secretaria de Vigilância em Saúde. Guia de vigilância em saúde. Brasília (DF); 2014.

14. Ministério da Saúde (BR). Sistema de Informações sobre Mortalidade - SIM. Brasília (DF); DATASUS; 2016.

15. Ministério do Trabalho e Emprego (BR). CBO - Classificação Brasileira de Ocupações - 4.0.3. Brasília (DF); 2016 [citado 27 set 2016]. Disponível em: http://www.mtecbo.gov.br/cbosite/ pages/home.jsf

16. Organização Mundial da Saúde. Classificação estatística internacional de doenças e problemas relacionados à saúde: 10ª revisão. São Paulo: Edusp; 2000.

17. Possas CA. Avaliação da situação atual do sistema de informação sobre doenças e acidentes do trabalho no âmbito da Previdência Social brasileira e propostas para sua reformulação. Rev Bras Saude Ocup. 1987 [citado 27 set 2016];15(60):43-67.Disponível em: http://www.scielo.br/ scielo.php?script=sci_issues\&pid=0303-7657\&lng=pt\&nrm=iso

18. Santana VS, Nobre LC, Waldvogel BC. Acidentes de trabalho no Brasil entre 1994 e 2004: uma revisão. Cienc Saude Coletiva. 2005;10(4):841-55. https://doi.org/10.1590/S1413-81232005000400009

19. Santana VS, Araújo-Filho JB, Albuquerque-Oliveira PR, Barbosa-Branco A. Acidentes de trabalho: custos previdenciários e dias de trabalho perdidos. Rev Saude Publica. 2006;40(6):1004-12. https://doi.org/10.1590/S0034-89102006000700007

20. Santana VS, Dias EC, Oliveira GL, Moura MCP, Nobre LCC, Machado JMH. Fatal work-related injuries and interpersonal violence in Brazil, 2000-2010. Salud Colectiva. 2013 [citado 27 set 2016];9(2):139-49. Disponível em: http://www.scielo.org.ar/pdf/sc/v9n2/en_v9n2a02.pdf

21. Saraiva A, Martins D. País ainda tem 44,2 milhões de trabalhadores informais, estima o IBGE. Valor Econ. 28 nov 2012 [citado 27 set 2017]. Disponível em: http://www.valor.com.br/ brasil/2919914/pais-ainda-tem-442-milhoes-de-trabalhadores-informais-estima-o-ibge 
22. Souza NSS, Portinho BG, Barreiros MF. Acidentes de trabalho com óbitos registrados em jornais no estado da Bahia. Rev Baiana Saude Publica. 2006;30(1):77-89.

23. Superintendência de Seguros Privados. Seguro DPVAT. Rio de Janeiro: SUSEPE; 2016. Disponível em http://www.susep.gov.br/setores-susep/cgpro/dpvat-1

24. Villela LCM, Rezende EM, Drumond EF, Ishitani LH, Carvalho GML. Utilização da imprensa escrita na qualificação das causas externas de morte. Rev Saude Publica. 2012;46(4):730-6. https://.doi.org/10.1590/S0034-89102012005000041

25. Waiselfisz JJ, Athias G. Mapa da violência de São Paulo. Brasília (DF): UNESCO; 2005.

Financiamento: Fundação de Amparo à Pesquisa do Estado de São Paulo (Fapesp - Processo 2014/03609-9). Fundo de Apoio à Pesquisa, Ensino e Extensão/Unicamp (FAEPEX - Processos 2014/609 e 2015/438). Conselho Nacional de Pesquisa (CNPq PIBIQ - Processo2016/100392-4).

Contribuição dos Autores: Concepção e planejamento do estudo: RC. Coleta, Análise e interpretação dos dados: RC, VGL, EAH, ACAM, LFT. Elaboração do manuscrito: RC, VGL, EAH, LFT. Aprovação da versão final: RC, VGL, EAH, ACAM, LFT. Responsabilidade pública pelo conteúdo do artigo: RC, VGL, EAH, ACAM, LFT.

Conflito de Interesses: Os autores declaram não haver conflito de interesses. 